\title{
Household task demands for quiet and focused behavior facilitate performance by ADHD youth
}

\author{
Demandas de tarefas domésticas por comportamento quieto e focado facilitam o \\ desempenho de jovens com TDAH \\ Camila Guimarães Mendes 1 , Adriana F. Drummond¹, Débora M. Miranda², Danielle S. Costa ${ }^{3}$, Marisa C. Mancini
}

\begin{abstract}
This study evaluated the associations among symptoms of attention-deficit/hyperactivity disorder (ADHD) and of oppositional defiant disorder (ODD) in children and adolescents' performance in household tasks and assistance provided by caregivers. Parents of children from 6 to 14 years old with ADHD ( $n=67)$ were interviewed with the Children Helping Out: Responsibilities, Expectations, and Supports (CHORES) instrument. Significant correlations were found between symptoms of ODD and assistance in self-care tasks $(r=-0.31$; $p=0.01)$; symptoms of hyperactivity correlated with assistance in self-care $(r=-0.30, p=0.01)$; and family-care $(r=-0.25, p=0.04)$ tasks. Age was directly associated with the number of tasks performed by children and inversely related to the assistance provided by caregivers. A greater number of ODD symptoms resulted in more household assistance from caregivers. Characteristics of ODD symptoms, such as disobedience and hostility in the face of authority, may limit these children in accessing household tasks by their own initiative, requiring assistance from caregivers.
\end{abstract}

Keywords: environment; behavior; attention deficit disorder with hyperactivity; caregivers.

\section{RESUMO}

Este estudo avaliou transversalmente a correlação entre sintomas de transtorno de déficit de atenção e hiperatividade (TDAH) e de oposição com desempenho de crianças e adolescentes nas tarefas domésticas e assistência disponibilizada pelos cuidadores. Pais de crianças e adolescentes com TDAH ( $n=67)$, de 6 a 14 anos, foram entrevistados com o children helping out: responsibilities, expectations and supports (CHORES). Foram encontradas correlações significativas entre sintomas de oposição e assistência em cuidado próprio ( $r=-0,31$; $p=0,01)$ e de hiperatividade com assistência em cuidado próprio $(r=-0,30, p=0,01)$ e em cuidado familiar $(r=-0,25, p=0,04)$. Idade está diretamente correlacionada ao número de tarefas desempenhadas pela criança e inversamente associada à assistência disponibilizada pelos cuidadores. Maior número de sintomas de oposição resultou em maior assistência disponibilizada. Características dos sintomas de oposição, como a desobediência e hostilidade frente às autoridades, são limitantes para que essas crianças acessem as tarefas por iniciativa própria, demandando maior assistência dos cuidadores.

Palavras-chave: meio ambiente; comportamento; transtorno do deficit de atenção com hiperatividade; cuidadores.

Attention-deficit/hyperactivity disorder (ADHD) is a heterogeneous condition associated with functional impact on several dimensions of a child's life ${ }^{1}$. This heterogeneity may be partially explained by the diversity of symptoms contributing to clinical presentations with distinct functional compromise $e^{2,3}$. $\mathrm{ADHD}$ is characterized by variable degrees of hyperactivity, impulsivity, and/or inattentive symptoms, affecting children's participation in school and in their household routine ${ }^{4}$.

In school, children with ADHD usually exhibit worse academic performance than children developing typically ${ }^{3,5}$. In addition, individuals with ADHD show difficulties in interpersonal relationships and emotional-behavioral control

${ }^{1}$ Universidade Federal de Minas Gerais, Departamento de Terapia Ocupacional, Belo Horizonte MG, Brasil;

${ }^{2}$ Universidade Federal de Minas Gerais, Departamento de Pediatria, Belo Horizonte MG, Brasil;

${ }^{3}$ Universidade Federal de Minas Gerais, Programa de Pós-graduação em Medicina Molecular, Belo Horizonte MG, Brasil.

Correspondence: Marisa Cotta Mancini; Departamento de Terapia Ocupacional, EEFFTO, Universidade Federal de Minas Gerais; Av. Antônio Carlos, 6627; 31270-901 Belo Horizonte MG, Brasil; E-mail:mcmancini@ufmg.br; marisacmancini@gmail.com.

Conflict of interest: There is no conflict of interest to declare.

Support: Financial support for this study was granted by the Brazilian government agencies Conselho Nacional de Desenvolvimento Científico e Tecnológico (CNPq), Coordenação de Aperfeiçoamento de Pesssoal de Nivel Superior (CAPES), the Fundação de Amparo à Pesquisa de Minas Gerais (FAPEMIG) and the Laboratório de Investigação Médica, Hospital das Clínicas da Faculdade de Medicina, Universidade de São Paulo (FMUSP) - LIM34 (Rehabilitation Sciences). Pró-Reitoria de Pesquisa from Universidade Federal de Minas Gerais (UFMG), Brazil, supported the English translation.

Received 09 July 2015; Received in final form 05 March 2016; Accepted 18 April 2016. 
and often have low self-esteem ${ }^{1,6}$. Psychiatric comorbidities affect almost $70 \%$ of individuals with ADHD and account for increases in the long-term complexity of $\mathrm{ADHD}^{7}$.

Oppositional defiant disorder (ODD) is frequently preceded by and associated with ADHD. ODD includes a pattern of negativistic, defiant, disobedient, and hostile behavior toward any authority figure ${ }^{8,9}$. Thus, it negatively affects the condition's course and prognosis, family dynamics, and the child or adolescent's academic and social functioning ${ }^{10,11,12}$. ODD increases the risk of conduct disorder and of antisocial personality disorder ${ }^{13}$ and thus, it is essential to account for ODD symptoms in ADHD research.

The household environment is a primary reference context for children, where the presence of ADHD leads to significant functional disturbances. Dunn and collaborators $^{14}$ showed that ADHD children were more dependent in performing household tasks than children developing typically, although children with ADHD performed a similar number of household tasks compared with their typical peers. These authors also observed that ADHD diagnosis along with age, the presence of an older sibling, the importance parents give to the child's involvement in family routine, and the parents' level of stress were predictors of the number of tasks performed by children and of the type of assistance provided by their parents for their household task performance. The home environment encompasses rich and intense parent-child interactive routines around the engagement in and performance of household chores; thus, it is likely to be sensitive to the course of ADHD and ODD. Uncovering the impact of ADHD and ODD symptoms on the functional profiles of children's household engagement may help shed light onto the functional manifestations of these disorders.

Till date, the impact of ADHD on household participation has traditionally been investigated by comparing ADHD children with children developing typically. Such an investigative strategy has provided evidence on comparative profiles of children with and without ADHD. However, ADHD is known to be a heterogeneous condition with a wide variation in the clinical presentation, presence and course of symptoms, and associated comorbidities; thus, distinct functional profiles within this group of children are possible ${ }^{15,16}$. Understanding how ADHD's different characteristics interact with and impact on the participation of children and adolescents in household tasks may contribute to the diagnostic process as well as help to guide clinical diagnostic and intervention procedures aimed towards this population in a more predictive manner (i.e., a quantitative/dimensional approach) ${ }^{17}$. In addition, the present study increased the age range that has been investigated so far, including children with ADHD from 6 to 14 years of age, thus adding to the age range from previous studies that included children and adolescents from 9 to 11 years of age.
The objective of this study was to assess the association between symptoms (i.e., inattention, hyperactivity-impulsivity, and oppositional and defiant behaviors) and potential confounders, such as age, gender, and intelligence, with ADHD children's performance in household tasks, as well as with the amount of caregiver assistance provided. This study also sought to identify predictive factors of ADHD children's participation in household tasks.

\section{METHOD}

\section{Participants}

Participants who attended the child psychiatry university outpatient clinic were recruited by convenience and included in the study according to the following criteria: age between 6 and 14 years, a medical diagnosis of ADHD, and a percentile of at least $10 \%$ in the Raven's progressive matrices test of intelligence (Raven's CP) ${ }^{18}$. All participants had recently started drug treatment (within no more than one month). Two subjects were excluded because they had history of seizures $(n=1)$ and associated head trauma $(n=1)$.

The study sample consisted of a group of 67 children and adolescents with $\mathrm{ADHD}$ and their parents or caregivers. They were divided into two age groups (6 to 10 years and 11 to 14 years). Participants' characteristics are presented in Table 1.

Regarding the sample's clinical characteristics, 30 children (44.7\%) had a mental disorder other than ADHD. Of these children, 21 (33.3\%) had ODD, seven (10.4\%) had anxiety disorders,

Table 1. Descriptive characteristics of the sample $(n=67)$.

\begin{tabular}{|cc}
\hline Characteristic & Frequency and (percent) \\
\hline ADHD children & \\
Age (years) & $47(70)$ \\
$6-10$ & $20(30)$ \\
$11-14$ & \\
Sex & $54(81)$ \\
\hline Male & $13(19)$ \\
\hline Female & \\
SES & $20(30)$ \\
\hline B & $45(67)$ \\
C & $02(03)$ \\
D & \\
Caregivers & \\
Respondents & $51(76)$ \\
\hline Mother & $5(7)$ \\
\hline Father & $11(16)$ \\
\hline Grandmother & \\
\hline Schooling & $3(4)$ \\
\hline Elementary & $30(44)$ \\
\hline High school & $4(5)$ \\
\hline Undergraduate & $43(12)$ \\
\hline Age (years)* & \\
\hline ADHD: attention-deficit hyperactivity disorder; SES: family socioeconomic \\
\hline
\end{tabular}

status; ${ }^{*}$ numbers indicate mean and (standard deviation). 
one (1.4\%) had autism spectrum disorder (ASD), and four (5.9\%) had hyperactivity. Regarding fluid intelligence, most children $(n=41)$ obtained a percentile over $50 \%$. The mean values for the sum of inattention, hyperactivity-impulsivity, and ODD symptoms were 19.7 ( $\mathrm{SD}=4.8), 18.3(\mathrm{SD}=5.9)$, and 11.9 $(\mathrm{SD}=5.9)$, respectively.

\section{Measures}

All subjects were diagnosed according to the DSM- $5^{19}$ criteria by an experienced pediatrician who was previously trained by a child psychiatrist. In order to guarantee consistency, examiners were tested and an agreement index of 98\% was obtained. The diagnostic protocol included parent and child interviews with the Brazilian version of the schedule for affective disorders and schizophrenia for school-age children/present and lifetime version (KSADS-PL) ${ }^{20}$, questionnaires to identify symptoms and their severity, neuropsychological tests, and clinical observations. The KSADS-PL was administered either by a child psychiatrist or by a resident (R4) with the diagnosis established by the combination between the results of the instrument (KSADS-PL) and the confirmatory interview conducted by the child psychiatrist.

The Brazilian version of Raven's $\mathrm{CPM}^{18}$ is a well-established non-verbal test of inductive reasoning and often regarded as a good marker of general intelligence. A trained neuropsychologist administered this test on all participants.

Families' socioeconomic level was classified by the criteria proposed by the Associação Brasileira das Empresas de Pesquisa ${ }^{21}$.

Parents completed the Brazilian version of the Swanson, Nolan, and Pelham-version IV (SNAP-IV) for evaluation of their children's ADHD symptoms ${ }^{22}$. This is a screening questionnaire for ADHD and oppositional defiant disorder (ODD) that is based on the "A" criteria established by the DSM ${ }^{19}$. The scale includes 26 items separated into three subscales: inattention, hyperactivity/impulsiveness, and oppositional behavior. The items are scored on a 4-point scale $(0=$ not at all, 1 = just a little, 2 = quite a bit, and 3 = very much $)^{22}$. Participants' symptoms were characterized by the sum of items' ratings for each subscale.

Children's participation in household tasks was documented using the Brazilian version of the children helping out: responsibilities, expectations, and supports (CHORES) instrument ${ }^{23}$. Parents and caregivers were interviewed with this 34-item structured questionnaire and provided information on the participation of their children and adolescents (ages 6 to 14 years) in household tasks, categorized into two subscales: self-care tasks and family-care tasks ${ }^{23,24}$. Self-care tasks refer to caring for own belongings and own needs, e.g., "puts away own clothes" and "makes self a snack." Family-care tasks include caring for family needs and belongings, e.g., "brings in or puts away groceries," "sets or clears the table," and "prepares part of a cold meal for the family" ${ }^{23}$. The performance and assistance scores for each task are added up, producing partial scores for the self-care and family-care subscales, as well as total scores. High performance scores suggest that the child performs a large number of household tasks; high assistance scores indicate self-initiated performance or greater independence in performing household tasks ${ }^{23,24,25}$.

The Brazilian-Portuguese version of the CHORES showed indices of test-retest reliability greater than 0.90, illustrating strong consistency when administered within an interval up to 14 days $^{23,25}$.

\section{Procedures}

The $\mathrm{CHORES}^{24}$ and the criteria proposed by the Brazilian Criterion of Economic Classification ${ }^{21}$ were administered during participants' visits to the child psychiatric outpatient clinic from the university hospital during an interview with parents, conducted by a single, previously trained examiner. The interviews lasted approximately $30 \mathrm{~min}$.

This study is part of a research project entitled "Multidimensional assessment of individuals with attention-deficit/hyperactivity disorder" from the Departamento de Pediatria, Faculdade de Medicina (UFMG), which was approved by the University's Ethics Review Committee (CAE: 02899412.9.0000.5149). All participants signed informed consent forms.

\section{Data Analyses}

Initial checking of the distributions was conducted to ensure that there were no violations of the assumptions of normality. The significance level was set at $\alpha=0.05$.

Frequency counts described participants according to their sociodemographic characteristics and fluid intelligence. Mean and standard deviation values summarized information on children's symptoms. Pearson's correlation coefficients tested bivariate associations between inattention, hyperactivity, ODD symptoms, and the descriptive variables (age and intelligence) with performance and assistance in self-care and family-care household tasks. Variables that showed significant associations with each of the outcomes were selected for the regression models. Finally, multiple regression analyses with stepwise selection tested the predictive strength of these variables with the household performance and assistance outcomes.

\section{RESULTS}

\section{Association between symptoms and demographic} features with children's performance and caregiver assistance in self-care and family-care tasks

Age was associated with performance and with caregiver assistance in both self-care and family-care household tasks; older children performed more tasks and showed more independence in household tasks. Fluid intelligence was not associated with either participation outcomes. There were significant correlations between hyperactive-impulsive symptoms 
and assistance in self-care and in family-care tasks, and between ODD symptoms and assistance in self-care tasks. These coefficients were negative and of weak to moderate magnitude. Table 2 shows these associations.

Analyses by age showed significant correlations between hyperactive-impulsive symptoms and assistance provided in self-care tasks ( $r=-0.55 ; \mathrm{p}=0.011$ ) only for the 11 to 14 -year-old age group. In this same age group, ODD symptoms were negatively associated with performance $(r=-0.49$; $p=0.044)$, assistance in self-care tasks ( $r=-0.59 ; \mathrm{p}=0.006)$, and assistance in family-care tasks $(r=-0.44 ; p=0.049)$. Analyses by gender revealed significant correlations only in the male group. Table 3 shows the correlation coefficients for the boys with ADHD.

\section{Predictors of household participation in children with ADHD}

ODD symptoms, but not ADHD symptoms, were predictive of assistance in self-care tasks. The higher the number of symptoms of ODD the higher is the assistance in self-care tasks among our participants with ADHD.

Regarding the importance among predictors of household participation, age was consistently present in all models (Table 4). Although hyperactivity-impulsivity showed a significant association with the outcomes in the preliminary bivariate analyses, its effect was not observed in the presence of other predictors.

Table 2. Pearson correlation coefficients describing the associations between symptoms, age, and fluid intelligence with attention-deficit/hyperactivity disorder (ADHD) child's performance in household tasks and assistance provided by caregivers.

\begin{tabular}{lcccc}
\hline Descriptive variables & PSC & PFC & ASC & AFC \\
Age & $0.38^{*}$ & $0.26^{*}$ & $0.43^{*}$ & $0.25^{\star}$ \\
Fluid intelligence & -0.17 & -0.22 & -0.18 & -0.20 \\
AD & 0.03 & 0.09 & 0,003 & 0.13 \\
HI & -0.21 & -0.23 & $-0.30^{*}$ & $-0.25^{\star}$ \\
OD & -0.23 & -0.18 & $0.31^{*}$ & -0.19
\end{tabular}

PSC: performance in self-care tasks; PFC: performance in family-care tasks; ASC: assistance in self-care tasks; AFC: assistance in family-care tasks; AD: attention-deficit symptoms; HI: hyperactivity-impulsivity symptoms; OD: oppositional symptoms; * significant correlation coefficient $(p<0.05)$.
Variance inflation factor (VIF) values between 1.0 and 2.0 revealed an absence of multicollinearity problems in the different predictors selected by the models.

\section{DISCUSSION}

In this study, we observed that hyperactivity-impulsivity severity, but not inattention, was associated with increased parental assistance in both self-care and family-care task performance. Additionally, ODD symptoms were associated with higher assistance in self-care tasks among our participants with ADHD. However, the associations seemed to be moderated by age and gender, with stronger coefficients observed among older children with ADHD (11 to 14 years old) and boys. The children's age was the strongest predictor of outcome in all models. These findings suggest that ADHD children's participation in household tasks tends to ameliorate with age (i.e., performance in more tasks and higher independence observed in older children). These results are in agreement with previous studies conducted in children with $\mathrm{ADHD}$, revealing a positive association between age and performance in self-care and family-care tasks; however, there was no correlation with assistance in household tasks. This difference could be explained by the inclusion of older
Table 3. Pearson correlation coefficients describing the associations between symptoms and performance of boys with attention-deficit/hyperactivity disorder (ADHD) in household tasks and assistance provided by caregivers.

\begin{tabular}{lcccc}
\hline Symptoms & PSC & PFC & ASC & AFC \\
\hline AD & 0.04 & 0.11 & 0.01 & 0.14 \\
HI & $-0.41^{*}$ & $-0.27^{*}$ & $-0.48^{*}$ & $-0.29^{*}$ \\
OD & $-0.36^{*}$ & -0.20 & $-0.39^{*}$ & -0.21 \\
\hline
\end{tabular}

PSC: performance in self-care tasks; PFC: performance in family-care tasks; ASC: assistance in self-care tasks; AFC: assistance in family-care tasks; AD: attention-deficit symptoms; HI: hyperactivity-impulsivity symptoms; OD: oppositional symptoms; * significant correlation coefficient $(p<0.05)$.

Table 4. Predictive models of attention-deficit hyperactivity disorder (ADHD) children's household participation.

\begin{tabular}{|c|c|c|c|c|}
\hline Predictive models of household participation & $\mathrm{B}$ & Error & VIF & $p$-value \\
\hline $\operatorname{PSC}\left(R^{2}=0.25, F=10.76\right)$ & & & & 0.001 \\
\hline Age (years) & 0.41 & 0.11 & 1.0 & 0.001 \\
\hline Gender & -2.12 & 0.71 & 1.0 & 0.004 \\
\hline $\operatorname{PFC}\left(R^{2}=0.06, F=4.59\right)$ & & & & 0.0001 \\
\hline Age (years) & 0.25 & 0.12 & 1.0 & 0.036 \\
\hline $\operatorname{ASC}\left(R^{2}=0.32, F=10.19\right)$ & & & & 0.0001 \\
\hline Age (years) & 2.26 & 0.55 & 1.003 & 0.0001 \\
\hline $\mathrm{OD}$ & -0.62 & 0.23 & 1.003 & 0.009 \\
\hline Gender & -8.18 & 3.45 & 1.001 & 0.021 \\
\hline $\operatorname{AFC}\left(R^{2}=0.06, F=4.43\right)$ & & & & 0.039 \\
\hline Age (years) & 1.32 & 0.63 & 1.0 & 0.039 \\
\hline
\end{tabular}

B: Beta coefficient; VIF:variance inflation factor; PSC: performance in self-care tasks; PFC: performance in family-care tasks; ASC: assistance in self-care tasks; OD: oppositional symptoms; AFC: assistance in family-care tasks. 
children and adolescents (ages 11 to 14 years) in our study, while the samples from previous studies were restricted to 9- to 11-year-olds. The use of various types and/or amounts of assistance to accomplish household tasks seems to be an issue among older children and adolescents.

The role of ODD symptoms in household task participation is also worth noting. For children with $\mathrm{ADHD}$, higher levels of ODD symptoms increased the assistance provided by caregivers in self-care tasks, even when taking age and gender into consideration. Engagement in household tasks is built on the daily parent-child relationships, which are influenced by their previous interactions, personalities, and preferences or expectations. While caregivers should allow children and adolescents to engage in household tasks and provide opportunities for their learning, children's ability to accept an adult's requests, orders, and/or guidance, as well as their readiness to start, continue, and repeat the domestic experiences that enable the construction of their independence, also play important roles ${ }^{14,23,26}$. Because ODD symptoms are characterized by negative, disobedient, and hostile behaviors toward authority figures ${ }^{8}$, they may restrict children from accessing household tasks by their own initiative, thus requiring more and sometimes constant assistance from their caregivers. It is possible that household task participation function as an indirect marker of the families that did or did not succeed in building an appropriate environment in which to engage their child with $\mathrm{ADHD}$ in the household routine.

Differently from the literature that reported school difficulties among children and adolescents with ADHD, our results showed that hyperactive-impulsive symptoms did not appear as relevant predictors of the household task participation models. This result could be explained by the relationship between these children and adolescents' behaviors and the specificities of household tasks, which affect the type and amount of effort demanded to perform them ${ }^{27}$. Hyperactivity is characterized by motor restlessness and difficulty in demonstrating focus and concentration to maintain task performance $^{22}$. For instance, some household tasks require greater body movement and spatial displacement (i.e., sweeping, cleaning, and setting the table) than school tasks. It is possible that hyperactive symptoms do not restrict children and adolescents with $\mathrm{ADHD}$ from engaging in and performing such tasks. In addition, parents tend to maintain control of the household environment and the routine is less formal and structured than that of the school environment. The decreased demands for quiet and focused behavior from household tasks compared with school tasks may contribute to facilitating the performance by ADHD children and adolescents ${ }^{28,29}$.

\section{Limitations}

No participant from this study had been taking medication for ADHD for more than four weeks. Consequently, our results do not capture the impact of medication on these children's engagement in household tasks. In addition, as most of our sample was derived from families of low-to-middle socioeconomic level, our results are restricted to household task participation typically observed in these socioeconomic classes. Investigations on the generalization of our results to higher SES families are warranted.

In conclusion, our study investigated how $\mathrm{ADHD}$ and ODD symptoms interact with and impact the participation of children and adolescents in household tasks. The role of such symptoms on household engagement by youth should be understood in combination with the characteristics of the family and home environment, which includes the types and quality of parent-child interactions, as well as the guidance and support provided by caregivers. In addition, the organization and structuring of the family's daily routine, the types of task demands, and the consistency with which children's and adolescents' household engagement is required seem to help set the stage to foster and/or hinder their participation at home.

\section{Acknowledgements}

Human support for this study was provided by members of the Núcleo de Investigações sobre a Impulsividade e Atenção (NITIDA) and faculty from the Departamento de Pediatria, Faculdade de Medicina, Universidade Federal de Minas Gerais, Brazil.

\section{References}

1. Klassen AF, Miller A, Fine S. Health-related quality of life in children and adolescents who have a diagnosis of attention-deficit/hyperactivity disorder. Pediatrics. 2004;114(5):541-7. doi:10.1542/peds.2004-0844

2. Engel-Yeger B, Ziv-On D. The relationship between sensory processing difficulties and leisure activity preference of children with different types of ADHD. Res Dev Disabil. 2011;32:1154-62. doi:10.1016/j.ridd.2011.01.008

3. Kawabata Y, Tseng WL, Gau SS. Symptoms of attention-deficit/hyperactivity disorder and social and school adjustment: the moderating roles of age and parenting. J Abnorm Child Psychol. 2012;40(2):177-188. doi:10.1007/s10802-011-9556-9
4. American Psychiatric Association. Diagnostic and statistical manual of mental disorders (DSM-IV), 4th ed. Washington, DC: American Psychiatric Association; 1994.

5. Wu S, Gau SS. Correlates for academic performance and school functioning among youths with and without persistent attention-deficit/hyperactivity disorder. Res Dev Disabil. 2013;34(1):505-15. doi:10.1016/j.ridd.2012.09.004

6. Garner AA, O'Connor BC, Narad ME, Tamm L, Simon JEpstein JN. The relationship between ADHD symptom dimensions, clinical correlates, and functional impairments. J Dev Behav Pediatr. 2013;34(7):469-77. doi:10.1097/DBP.0b013e3182a39890. 
7. Barbaresi WJ, Colligan RC, Weaver AL, Voigt RG, Killian JM, Katusic SK. Mortality, ADHD, and psychosocial adversity in adults with childhood ADHD: a prospective study. Pediatrics. 2013;131(4):637-44. doi:10.1542/peds.2012-2354

8. Loeber R, Burke JD, Pardini DA. Development and etiology of disruptive and delinquent behavior. Ann Rev Clin Psychol. 2009;5:291-310. doi:10.1146/annurev.clinpsy.032408.153631

9. Burke JD, Loeber R, Lahey BB, Rathouz PJ. Developmental transitions among affective and behavioural disorders in adolescent boys. J Child Psychol Psychiatry. 2005;46:1200-10. doi:10.1111/j.1469-7610.2005.00422.x

10. Dunn L, Coster WJ, Orsmond GI, Cohn ES. Household task participation of children with and without attentional problems. Phys Occup Ther Pediatr. 2009;29(3):258-73. doi:10.1080/01942630903008350

11. Danforth JS, Connor DF, Doerfler LA. The Development of Comorbid Conduct Problems in Children With ADHD: An Example of an Integrative Developmental Psychopathology Perspective. J Atten Disord. 2014;10:1-16. doi:10.1177/1087054713517546

12. Possa MA, Spanemberg L, Guardiola A. Attention-deficit hyperactivity disorder comorbidity in a school sample of children. Arq Neuropsiquiatr. 2005;63(2B):479-83. doi:10.1590/S0004-282X2005000300021

13. Pastura G, Mattos P, Araújo AQ. Prevalence of attention deficit hyperactivity disorder and its comorbidities in a sample of school-aged children. Arq. Neuropsiquiatr. 2007;65(4A):1078-1083. doi:10.1590/S0004-282X2007000600033

14. Biederman J, Monuteaux, MC, Spencer T, Wilens TE, Macpherson HA, Faraone SV. Stimulant therapy and risk for subsequent substance use disorders in male adults with ADHD: a naturalistic controlled 10-year follow-up study. Am J Psychiatry. 2008;165(5):597-603. doi:10.1176/appi.ajp.2007.07091486

15. Willcutt EG, Nigg JT, Pennington BF, et al. Validity of DSM-IV attention deficit/hyperactivity disorder symptom dimensions and subtypes. J Abnorm Psychol. 2012;121(4):991-1010. doi:10.1037/a0027347

16. Takeda T, Ambrosini PJ, deBerardinis R, Elia J. What can ADHD without comorbidity teach us about comorbidity? Res Dev Disabil. 2012;33(2):419-25. doi:10.1016/j.ridd.2011.09.024

17. Mulligan A, Anney R, Butler L et al. Home environment: association with hyperactivity/impulsivity in children with ADHD and their non-ADHD siblings. Child: care, health develop. 2013;39(2):202-12. doi:10.1111/j.1365-2214.2011.01345.x

18. Pasquali L, Wechsler S, Bensusan E. Raven's Colored Progressive Matrices for Children: a validation study for Brazil. Aval Psicol. 2002;1(2):95-110.
19. American Psychiatric Association. Diagnostic and statistical manual of mental disorders (DSM-5), 5th ed. Washington, DC: American Psychiatric Association; 2013.

20. Kaufman J, Birmaher B, Brent D et al. Schedule for affective disorders and schizophrenia for school-age children present and lifetime version (K-SADS-PL): initial reliability and validity data. J Am Acad Child Adolesc Psychiatry. 1997;36(7):980-8. doi:10.1097/00004583-199707000-00021

21. Brazilian Association of Research Companies. Brazil socioeconomic criteria (CCEB) 2012. Available at:〈http://www.abep.org.br〉. Accessed on June 30, 2015.

22. Mattos P, Serra-Pinheiro MA, Rohde L, Pinto D. A Brazilian version of the MTA-SNAP-IV for evaluation of symptoms of attention-deficit/hyperactivity disorder and oppositional-defiant disorder. Rev Psiquiatr. 2006;28(3):290-7. doi:10.1590/S0101-81082006000300008

23. Amaral MF, Paula RL, Drummond AF, Dunn L, Mancini MC. Translation of the children helping out-responsibilities expectations and supports (CHORES) questionnaire into Brazilian-Portuguese: Semantic, idiomatic, conceptual and experiential equivalences and application in normal children and adolescents and in children with cerebral palsy. Braz J Phys Ther. 2012;16(6):515-22. doi:10.1590/S1413-35552012000600011

24. Dunn L. Validation of the CHORES: A measure of school aged children's participation in household tasks. Scand J Occup Ther. 2004;11:179-90. doi:10.1080/11038120410003673

25. Amaral MF, Drummond AF, Coster W, Mancini MC. Household task participation of children and adolescents with cerebral palsy, Down syndrome and typical development. Res Dev Disabils. 2014;35(2):414-22. doi:10.1016/j.ridd.2013.11.021

26. Drummond AF, Gomes AMR, Coster WJ, Mancini, MC. Predictive factors of household task participation in brazilian children and adolescents. OTJR. 2015;35(2):101-9. doi:10.1177/1539449215573005

27. American Occupational Therapy Association. Occupational therapy practice. framework: domain and process. 2nd. AJOT. 2008;63(6):625-83.

28. Anaby D, Law M, Coster W et al. The mediating role of the environment in explaining participation of children and youth with and without disabilities across home, school, and community. Arch Phys Med Rehabil. 2014;95(5):908-17. doi:10.1016/j.apmr.2014.01.005

29. Froehlich TE, Lanphear BP, Epstein JN, Barbaresi WJ, Katusic SK, Kahn RS. Prevalence, recognition, and treatment of Attention-deficit/ hyperactivity disorder in a national sample of US children. Arch Pediatr Adolesc Med. 2007;161(9):857-64. doi:10.1001/archpedi.161.9.857 